\title{
Um olhar crítico sobre a sociometria da língua portuguesa
}

Cláudia Roncarati (UFF/CNPq)

Diego Barbosa da Silva (UFF/CAPES/Arquivo Nacional)

Letícia Cao Ponso (UFF/CAPES)

\section{Resumo}

A sociometria, isto é, os estudos que visam elaborar rankings e hierarquias entre as linguas, é abordada de maneira crítica neste artigo, a partir de dois problemas envolvendo a lingua portuguesa. O primeiro refere-se à defesa da lusofonia frente às demais linguas e fonias, numa tentativa de manter uma unidade linguística entre os países de lingua oficial portuguesa. O segundo alude-se à assimetria existente, mas por vezes intencionalmente ignorada entre as variedades do português. Como tema polêmico, as pesquisas sociométricas apresentam grande divergência tanto quanto de critérios de medição quanto de intenções dos autores que motivam e direcionam esses estudos. Desse modo, elas alimentam uma competição que não encontra fundamentos linguísticos, mas que atende muito bem aos interesses politicos, sociais, ideológicos e econômicos dos Estados ao mesmo tempo em que apaga a afirmação da diversidade e da heterogeneidade. É neste contexto em que se insere a ainda frágil ideia de lusofonia.

Palavras-chave: língua portuguesa; variedade linguística; lusofonia; sociometria. 


\section{Introdução}

A avaliação e a ponderação da importância relativa das línguas - sejam consideradas base da identidade nacional ou mercadoria em tempos de globalização - têm feito parte da agenda dos linguistas, que por vezes usam métodos estatísticos, matemáticos e demográficos para tal medição. Desse modo, é habitual encontrarmos pesquisas de cunho comparatista (elaboração de rankings) de toda a natureza. Trata-se de diagnósticos que se baseiam em critérios muitas vezes flutuáveis e variáveis, os quais podem recortar ou falsear os dados, já que muitas vezes propendem a mostrar aspectos da língua favoráveis a alimentar o ufanismo e o nacionalismo do autor. Tais estudos pressupõem uma homogeneidade no tratamento das línguas que muito mais idealiza uma comunidade de fala transnacional do que reflete uma realidade de práticas linguísticas, necessariamente heterogênea, tanto pelos fatores sócio-econômicos, históricos e simbólicos que cercam as línguas quanto pelas suas estruturas.

Quem mede hoje o peso de uma língua? E com que finalidade? Como garantir a clareza de critérios e o rigor de tais métodos de ponderação? Sem dúvida, não se trata de uma tarefa fácil, muito menos precisa, já que, por envolver questões de identidade, prestígio e poder econômico, é impossível deixar de lado o caráter subjetivo dos critérios escolhidos. Além disso, segundo Calvet (2006, p. 43) e Hamel (2008a, p. 68), o peso das línguas é relacional, ou seja, não se pode avaliar a situação de uma língua em si mesma, apenas em relação às outras línguas. Esses autores apresentam modelos segundo os quais "as línguas do mundo se integram em um esquema hierárquico, no qual as línguas de um nível inferior se veem atraídas pelas línguas dos níveis superiores (efeitos de gravitaçãoำ e circulam em sua galáxia" (HAMEL, 2008a, p. 68).

O presente artigo discute dois problemas relacionados à sociometria dos estatutos da língua portuguesa em suas dimensões geopolíticas, econômico-culturais e interétnicas. O primeiro deles diz respeito ao comprometimento da sociometria do português com fatores de defesa da lusitanidade: a lusofonia bem como as outras fonias (francofonia, hispanofonia, anglofonia) sustentam um

1 O modelo gravitacional proposto por Calvet (2006, p. 60) sugere que em torno de uma língua hipercentral, o inglês, gravitam uma dezena de linguas supercentrais, como o francês, o chinês, o espanhol, o árabe, o português. Em torno dessas línguas supercentrais gravitam de cem a duzentas linguas centrais, que são o centro de cinco a seis mil línguas periféricas. discurso de manutenção da unidade política nacional através da supremacia da língua majoritária e fundamentam-se no poder advindo do colonialismo (MARGARIDO, 2000; FARACO, 2009; FIORIN, 2009; NASCIMENTO, 2009). Tal defesa da língua abarca ao mesmo tempo uma concorrência entre as principais línguas supercentrais, bem como uma resposta à ameaça da supremacia do inglês como língua hipercentral (CALVET, 2007; HAMEL, 2008b).

O segundo problema, associado ao anterior, diz respeito à assimetria entre as variedades nacionais da língua portuguesa no cenário geopolítico internacional. Num âmbito geral, o crescente interesse dispensado ao nosso idioma se restringe ao cotejo entre 
o português europeu e o português brasileiro e exclui as outras variedades nacionais da língua portuguesa em seus espaços simbólicos de identidades e diversidades africanas e asiáticas. Tais variedades não nativas do português ${ }^{2}$ representam um patrimônio linguístico e cultural que ainda não foi suficientemente mapeado pela pesquisa linguística do português (ZOPPI-FONTANA, 2009; RONCARATI, 2011) nem serve de base para políticas de cooperação cultural que façam sentido para a vida cotidiana dos cidadãos da Comunidade de Países de Língua Portuguesa (CPLP), por exemplo (NASCIMENTO, 2009). O que se apresenta hoje nada mais é do que o continuísmo dessa assimetria, que sequer é discutida pelos países nela envolvidos (FARACO, 2009; NAMBURETE, 2009; NASCIMENTO, 2009). Não obstante, no espaço político da enunciação linguística, os discursos oficiais dos governos perpetuam ideias de cooperação com base em uma idealização de língua comum sem que, no entanto elas produzam efeito na implementação de uma política linguística concreta e eficaz.

O artigo move-se no âmbito teórico das pesquisas sociométricas das línguas do mundo como uma área de estudos polêmica e atual. Entendemos aqui como estudos sociométricos tanto os de enfoque mais quantitativo, que contabilizam o número de falantes, estabelecendo rankings para as línguas segundo critérios variados (CRYSTAL, 1997; CALVET, 2006 e 2007; HAMEL, 2008a e 2008b), quanto os que categorizam as línguas estabelecendo entre elas uma hierarquia de status e funções (modelo gravitacional de CALVET, 1999; esquema de círculos concêntricos de KACHRU, 1986). Também dialogamos com análises recentes na literatura brasileira sobre a difusão transnacional da língua portuguesa (ZOPPI-FONTANA, 2009 e RONCARATI, 2009 e 2011).

\section{A controversa mensuração da importância relativa das línguas: o lugar do português}

No ambiente caracterizado por Louis-Jean Calvet (2007) como "a guerra das línguas", é comum aos nacionalistas convictos, de maneira geral, utilizar variáveis ou dados de pesquisa que aparentemente favoreçam sua língua frente às demais. Um chinês dirá que sua língua é a mais falada no mundo em número absoluto de falantes em vez de dizer que só existe um único prêmio Nobel de Literatura em língua chinesa; um francês preferirá dizer que sua língua é falada em 27 países em vez de dizer que é apenas a décima sexta mais falada em número absoluto de indivíduos; um alemão preferirá dizer que existem 114 ganhadores de língua alemã do prêmio Nobel, sendo treze de literatura, em vez de dizer de dizer que sua língua é falada apenas na Europa (LEWIS, 2009; PRÊMIO NOBEL, 2011; DEUTSCHLAND, 2010). Logo, tentar elevar a condição de seu idioma não é uma característica restrita

$2 \mathrm{Ou}$ VNN, segundo Perpétua Gonçalves (2010). 
O caráter relativista e a flutuação de critérios das pesquisas sociométricas sobre as línguas supercentrais serão mostrados a seguir por meio de cinco critérios comumente usados para medir a importância de uma língua (cada um com suas restrições). São eles: a) número de falantes como língua materna, b) número de países e continentes em que é língua oficial, c) línguas mais utilizadas na internet, d) peso econômico dos países nos quais essas línguas são oficiais, e) quantidade de pr3êmios Nobel de Literatura por língua.

\subsection{Número de falantes}

O número de falantes de uma determinada língua usada como língua materna (L1) é sem dúvida o critério mais utilizado na medição do peso das línguas. Cinco fontes de rankings que usam esse critério foram selecionadas para compor o quadro abaixo:

3 Disponível em: $<$ http://www.ethnologue.com/>. Acesso em 25 de julho de 2011.

4 Disponível em: $<$ http://observatorio-lp. sapo.pt/pt $>$. Acesso em 25 de julho de 2011.

5 Disponível em: <http://pt.wikipedia. org/wiki/Anexo:Lista_ de_1\% C3\% ADnguas_ por_total_de_falantes>. Acesso em 25 de julho de 2011. Ainda que a wikipedia não seja uma fonte confiável, devido a sua manipulação por qualquer usuário da internet, seus dados podem ser considerados , não pelos números em si, mas como mais uma marca desse ufanismo, tanto que os dados da wikipedia em língua portuguesa são diferentes da wikipedia em língua inglesa.

6 Disponível em: <http://www.abec.ch/ Portugues/subsidios-educadores/artigos/ categorias/artigos-familia/Portugues_e_a_ sexta_lingua_materna_ mais_falada_no_mundo.pdf $>$. Acesso em 25 de julho de 2011.

${ }^{7}$ Disponível em: <http:// frankherles.wordpress. com/2008/10/29/os-100-idiomas-mais-falados-do-mundo/>. Acesso em 25 de julho de 2011.
Quadro 1: As línguas mais faladas do mundo (em milhões)

\begin{tabular}{|c|c|c|c|c|c|c|c|c|c|c|}
\hline & $\begin{array}{l}\text { Ethnologu } \\
\text { (1995) }\end{array}$ & & $\begin{array}{l}\text { Observatóri } \\
\text { da Língua } \\
\text { Portuguesa } \\
\text { 2010) }\end{array}$ & 1995- & $\begin{array}{l}\text { Wikipedia } \\
\text { português }\end{array}$ & $\begin{array}{l}\text { em } \\
(2011)\end{array}$ & Unesco (2 & 00) & $\begin{array}{r}\text { Worlc } \\
\text { Observa } \\
(200\end{array}$ & \\
\hline 1 & Chinês & & $\begin{array}{l}\text { Chinês } \\
\text { (Mandarim) }\end{array}$ & 845 & Chinês & 1300 & $\begin{array}{l}\text { Manda- } \\
\text { rim }\end{array}$ & 874 & Chinês & 1081 \\
\hline 2 & Espanhol & 329 & Espanhol & 329 & Hindi & 422 & Hindi & 366 & Inglês & 355 \\
\hline 3 & Inglês & 328 & Inglês & 328 & Espanhol & 406 & Espanhol & 358 & Espanhol & 298 \\
\hline 4 & Árabe & 221 & Português & 240 & Inglês & 375 & Inglês & 341 & Hindi & 288 \\
\hline 5 & Hindi & 182 & Hindi & 182 & Árabe & 280 & Bengali & 289 & Português & 236 \\
\hline 6 & Bengali & 181 & Bengali & 181 & Português & 249 & Português & 176 & Bengali & 199 \\
\hline 7 & Português & 178 & Russo & 144 & Bengali & 171 & Russo & 167 & Malaio & 198 \\
\hline 8 & Russo & 144 & Japonês & 122 & Russo & 170 & Japonês & 100 & Russo & 164 \\
\hline 9 & Japonês & 122 & Alemão & 90 & Japonês & 125 & $\mathrm{Wu}$ & 77 & Japonês & 127 \\
\hline 10 & Alemão & 90,3 & Javanês & 85 & Francês & 110 & & & Francês & 108 \\
\hline 11 & Javanês & 84,6 & & & Alemão & 110 & & & Alemão & 108 \\
\hline 12 & Lahnda & 78,3 & & & & & & & Persa & 98 \\
\hline
\end{tabular}

Fontes: Ethnologue, 20093; Observatório da Língua Portuguesa, 20114; Wikipedia em português, 2011'; Unesco, 20096; World's Observatory, $2007^{7}$.

Evidentemente, a coleta desses dados não é uma tarefa simples, devido ao volume de trabalho e de recursos, embora ela possa ser obtida a partir de um censo, isto é, de uma mera contagem. Entretanto, geralmente os censos populacionais não incluem informações linguísticas em suas entrevistas.

Além disso, esses rankings de línguas apoiam-se em pesquisas com metodologias variadas, quando não utilizam referências de anos diferentes, como o Ethnologue (2009), que, para contabilizar os falantes de língua portuguesa, por exemplo, utiliza dados de 1993 para Angola, de 1999 para São Tomé e Príncipe, de 2004 para Cabo Verde, de 2005 para Guiné-Bissau e de 2006 para Moçambique. O mesmo ocorre com as línguas autóctones de cada país: para Angola, por exemplo, os dados sobre o chocue são de 
1991, os de umbundo são de 1995, os de quimbundo de 1999, os de ndonga são de 2000, os de quicongo são de 2007, e assim por diante, com as 41 línguas do país. Isso se aplica para as estatísticas de todos os países multilíngues no Ethnologue, o que compromete a comparabilidade dos dados.

Como se observa no quadro 1 , tem-se em mãos uma série de fontes com dados divergentes. Pode-se imaginar que tal divergência se deva à dificuldade de se encontrarem dados demográficos do mesmo ano para todas as fontes. Mas ainda que houvesse censos linguísticos do mesmo ano, o que em princípio aumentaria o rigor na comparação, não necessariamente os números coincidiriam, pois a discrepância também se deve aos diferentes critérios de medição seguidos por parte das agências, os quais não são explicitados nos sites que publicam os dados.

Por exemplo, comparando-se as fontes 1 e 2, o Ethnologue e o Observatório da Língua Portuguesa (órgão oficial apoiado pelo governo português), nota-se que o número de falantes de todas as outras línguas é exatamente igual nas duas fontes; exceção feita para o português, que, conforme a primeira fonte, ocupa a sétima posição, com 178 milhões de falantes, mas de acordo

${ }^{8}$ Entre eles estão: o número de falantes como segunda língua; número de falantes como língua estrangeira; número de países nos quais a língua é oficial ou cooficial; número de países nos quais é possível estudar essas línguas no ensino médio e no ensino superior; tradução a partir das línguas (línguas-fontes); tradução para as línguas (línguas-alvo); presença das línguas na Internet; possibilidade de consulta nas línguas no Google ou no Yahoo; possibilidade de consultar Wikipedia nas línguas; existência de corretores ortográficos nas línguas; índice de desenvolvimento humano dos países nos quais essas línguas são faladas; crescimento demográfico dos países nos quais essas línguas são faladas; peso econômico dos países nos quais essas línguas são faladas; produção/exportação de livros escritos nas diversas línguas; Prêmios Nobel de Literatura obtidos por autores que escreveram em uma determinada língua; fluxo de turistas; línguas de relações econômicas $(\mathrm{OMC})$; entropia e etc. com a segunda fonte é alçado à quarta posição, com 240 milhões de falantes. Como todas as pesquisas abrangem um período de cerca de quinze anos, a alteração demográfica não deveria ser tão significativa (aumento de 75 milhões de falantes de português em dez anos); além disso, o aumento demográfico deveria ocorrer também para falantes das outras línguas.

Assim, percebe-se que, dependendo da metodologia da pesquisa ou do censo, ou mesmo de interesses específicos, no quadro acima a língua portuguesa varia da quarta à sétima posição, a inglesa da segunda à quarta e a espanhola da segunda à terceira.

Para a escolha dos outros critérios, utilizamos a pesquisa de Calvet (2007), um dos pioneiros nos estudos da sociometria e também o criador do Barômetro Calvet, uma tentativa de calcular o peso das línguas levando em consideração diversos critérios ${ }^{8}$. Vejamos quatro deles a seguir.

\subsection{Número de países e continentes em que é língua oficial}

Observando-se o quadro a seguir, pode-se notar que o inglês é língua oficial de 55 países, enquanto o francês ocupa o segundo lugar com 27 países e o árabe, o terceiro com 24 países. O espanhol vem em quarto com 20 países, e o português, em quinto com 9 países. O chinês, língua mais falada do mundo como materna, é língua oficial de apenas 3 países. Se levarmos em consideração os continentes, veremos que o inglês é a única língua oficial em países de todos os continentes. O francês e o português viriam em segundo, presentes em quatro continentes (exceto na Ásia, no caso do francês e na Oceania, no caso do português). 
Quadro 2: Número de países e continentes em que é língua oficial

\begin{tabular}{|l|c|c|c|}
\hline \multicolumn{1}{|c|}{ Língua } & $\begin{array}{c}\text { Número } \\
\text { de países em } \\
\text { que é oficial }\end{array}$ & $\begin{array}{c}\text { Número } \\
\text { de continentes em } \\
\text { que é oficial }\end{array}$ & $\begin{array}{c}\text { Número em milhões } \\
\text { de falantes maternos } \\
\text { (Ethnologue, 1995) }\end{array}$ \\
\hline Inglês & 55 & 5 & 328 \\
Francês & 27 & 4 & 67,8 \\
Árabe & 24 & 2 & 221 \\
Espanhol & 20 & 3 & 329 \\
Português & 9 & 4 & 178 \\
Alemão & 5 & 1 & 90,3 \\
Suaíle & 4 & 1 & 0,5 \\
Italiano & 3 & 1 & 61,7 \\
Bengali & 2 & 2 & 181 \\
Russo & 2 & 1 & 144 \\
Hindi & 1 & 1 & 182 \\
Japonês & 1 & 1 & 122 \\
\hline
\end{tabular}

Fonte: Elaborado por Barbosa da Silva (2011) com dados do The New York Times Almanac 2009 e do Ethnologue 2009.

Vale ressaltar aqui que esse critério está diretamente relacionado à formação dos antigos impérios coloniais. As línguas no topo dessa lista - inglês, francês, espanhol, português - são justamente as línguas utilizadas na colonização linguística, que permaneceram oficiais mesmo após a descolonização. Por trás desses números, muitas vezes esconde-se uma tendência etnocêntrica e hegemônica, herdada da ideologia colonial, que insiste em se perpetuar sob novas roupagens: as diversas fonias (lusofonia, anglofonia, francofonia, hispanofonia) assentam-se em um terreno que ainda não apagou nem fez uma revisão crítica sobre a história recente, que subjugou, a ferro e a fogo, as línguas autóctones dos países colonizados, especialmente os de África.

A ideologia de "uma língua, uma nação" (EXTRA; YAĞMUR, 2004), surgida com o nacionalismo no séc. XIX (HOBSBAWM, 1990; ANDERSON, 2008), pressupõe que a unidade nacional é um requisito para a ascensão e o sucesso da nação como um todo. Obviamente, tal ambição não encontra respaldo nas práticas lin- 
guísticas heterogêneas da população da maioria dos países, nem procura responder às demandas gerais ou aos sentimentos identitários dos falantes. Assim, de certa forma, o multiculturalismo, os regionalismos, o tribalismo, as minorias étnicas e linguísticas são vistos pelo Estado-nação como uma ameaça, por representarem um obstáculo à sua unidade política. Como exemplos, temos as políticas anti-imigração e a xenofobia de alguns estados europeus, as políticas educacionais monolíngues em países cuja maioria da população é bilíngue.

O mais importante a destacar nesse quadro 2 é que nem sempre o caráter de oficialidade significa que a língua é usada pela maioria dos falantes. No caso do português dos Países Africanos de Língua Oficial Portuguesa (PALOP), o universo cultural da esmagadora maioria dos falantes é veiculado nas línguas vernáculas, as línguas bantu (FIRMINO, 2002; GONÇALVES, 2010; PONSO, 2011a).

Retornando ao quadro 2, podemos ver algumas das línguas mais faladas no mundo como materna versus o número de países e continentes em que é língua oficial. A língua portuguesa ocupa a sétima posição em número de falantes, mas se for considerada sua presença como oficial em continentes, ela salta para a segunda posição, perdendo apenas para o inglês e ocupando o mesmo lugar do francês. O importante disso tudo é que nessa competição entre línguas existem muitas variáveis possíveis para compará-las, mas o autor ufanista tende a utilizar aquelas que apresentam maiores vantagens, aparentemente, para a língua portuguesa. Ele tende a selecionar pontos de vista em que o português pareça superior às demais línguas do mundo, a fim de alterar o estatuto político da língua.

\subsection{Línguas utilizadas na internet}

O gráfico 1 apresenta o número de usuários da internet de acordo com a língua que utilizam. O inglês aparece na primeira posição com 536, 6 milhões de usuários, seguido pelo chinês com 444,9 milhões, pelo espanhol com 153,3 milhões, pelo japonês com 99,1 milhões e pelo português, em quinto lugar, com 82,5 milhões. Neste critério, o alemão, o francês, o russo e o coreano também apareceriam entre as dez línguas mais utilizadas. 
Gráfico 1: Línguas utilizadas na internet

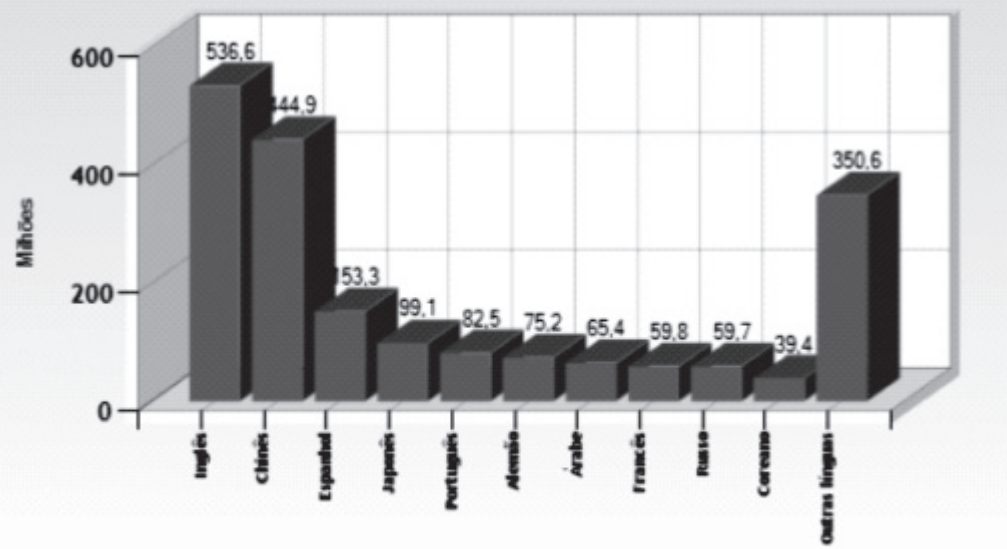

Linguas

$\mathrm{N}^{0}$ de utilizadores

Fonte: Observatório da Língua Portuguesa, $2011^{9}$.

Esse critério é interessante, por duas razões. A primeira, porque representa a globalização, por meio de um espaço atual e de crescimento acelerado, que é a internet. Trata-se de um espaço em que diversas línguas podem circular e dividir uma mesma página.

A segunda razão seria justamente a influência direta que esse critério sofre do poder aquisitivo dos usuários da internet. Ele assim favoreceria os usuários de línguas japonesa, francesa, alemã e coreana, que ganhariam algumas posições por apresentarem maior poder aquisitivo que os falantes de língua portuguesa, árabe ou russa.

\subsection{Peso econômico dos países nos quais as línguas são oficiais}

O quarto critério a ser observado é o peso econômico dos países nos quais essas línguas são oficiais. Para isso utilizamos dados do Fundo Monetário Internacional (FMI) e da Central Intelligence Agency of the United States (CIA), que, apesar de alguma variação, não alteraram a posição dos conjuntos de países agrupados pela língua oficial. Isolados em primeiro lugar, estão os países de língua oficial inglesa, com um PIB de mais de vinte bilhões de dólares. Em segundo lugar vêm os países de língua chinesa com PIB de aproximadamente 6,5 bilhões. Em terceiro viria o único país de língua oficial japonesa, o Japão, com o PIB de aproximadamente 5,5 bilhões de dólares, seguido de perto pelo

9 Disponível em: <http://www.observatorio-lp.sapo.pt/pt> Acesso em 28 jul. 2011. grupo de língua francesa, e depois pelos grupos de língua alemã, língua espanhola e língua italiana. Os nove países de língua oficial portuguesa teriam um PIB somado de aproximadamente 2,4 
bilhões de dólares, que os deixaria na oitava posição, atrás dos quatro países de língua italiana e seguido bem de perto pelos países de língua árabe.

Quadro 3: Peso econômico dos países nos quais as línguas são oficiais

\begin{tabular}{|l|c|c|}
\hline & $\begin{array}{c}\text { PIB (bilhões) } \\
\text { FMI }\end{array}$ & $\begin{array}{c}\text { PIB (bilhões) } \\
\text { CIA }\end{array}$ \\
\hline Países de língua oficial inglesa & 23,138 & 22,944 \\
Países de língua oficial chinesa & 6,755 & 6,420 \\
País de língua oficial japonesa & 5,458 & 5,391 \\
Países de língua oficial francesa & 5,318 & 5,288 \\
Países de língua oficial alemã & 4,214 & 4,199 \\
Países de língua oficial espanhola & 4,101 & 4,064 \\
Países de língua oficial italiana & 2,578 & 2,561 \\
\hline Países de língua oficial portuguesa & 2,432 & 2,347 \\
\hline Países de língua oficial árabe & 2,295 & 2,162 \\
Países de língua oficial russa & 1,664 & 1,664 \\
Países de língua oficial bengali & 1,641 & 1,535 \\
Países de língua oficial híndi & 1,537 & 1,430 \\
Países de língua oficial neerlandesa & 1,248 & 1,237 \\
Países de língua oficial coreana & 1,007 & 1,014 \\
\hline
\end{tabular}

Fontes: Fundo Monetário Internacional, 200910; Central Intelligence Agency of the United States, $2010^{11}$.

Quanto à relação entre língua e dinheiro, Bethania Mariani (2011, p. 4) aponta que não é algo recente: "Filósofos como Locke, Leibniz e Hume e economistas como Adam Smith, Marx e Weber escreveram sobre a analogia, enfatizando ora a função que a língua e o dinheiro têm na sociedade, ora o valor que ambos têm como poder de barganha". Por outro lado, Zoppi-Fontana (2009) aponta para o surgimento recente de um mercado linguístico no mundo globalizado, num processo de capitalização linguística.

O processo de capitalização linguística se caracteriza por investir uma língua de valor de troca, tornando-a ao mesmo tempo em bem de consumo atual (mercadoria) e um investimento

10 Disponível em: <http://www.imf.org/ external/index.htm> Acesso em: 28 jul. 2011.

11 Disponível: <https:// www.cia.gov/> Acesso em: 28 jul. 2011. em mercado de futuros, isto é, cotando seu valor simbólico em termos econômicos. Desta maneira, as línguas, que sempre foram arma de dominação política nos processos de colonização, se tornam na contemporaneidade novo mecanismo de especulação financeira e, consequentemente, de dominação econômica para 
um mundo em que as línguas se tornaram mercadorias, o mais novo e rentável bem de capital cuja posse seria necessária para que o indivíduo contemporâneo possa se inscrever enquanto sujeito de Mercado no mundo globalizado. Em outras palavras, observamos um forte processo de mercantilização das línguas (ZOPPI-FONTANA, 2009, p. 37).

Como exemplos disso temos o acordo ortográfico, que entre suas justificativas está a unificação dos mercados editoriais, ou o crescimento do mercado de ensino de Português como Língua Estrangeira (PLE), comprovado nos trabalhos de Zoppi-Fontana (2009) e Diniz (2010).

O crescimento do mercado de PLE pode também ser observado a partir da adoção de leis que garantam a oferta de PLE no ensino público de diversos países vizinhos daqueles de língua oficial portuguesa nesses últimos anos, como o Uruguai (2008), a Argentina (2009), a Venezuela (2009), a Espanha/Extremadura (2009), a Zâmbia (2009) e o Congo (2010) (ÁFRICA 21, 2009; RATTNER, 2010).

Tal crescimento do espaço da língua portuguesa, observado, sobretudo nesta última década, deve ser analisado a partir dos esforços do Brasil de se projetar internacionalmente como futura potência mundial. Assim, à medida que o Brasil se projeta politicamente, eleva-se o estatuto do português brasileiro como língua transnacional substituindo a primazia que até então tinha o português europeu. Por sua vez, um maior estatuto do português brasileiro favoreceria ainda mais a projeção do país.

Entre os acontecimentos que favoreceram a projeção do português brasileiro, pode-se citar o grande crescimento econômico de todos os países do BRICS (Brasil, Rússia, Índia, China e mais recente a África do Sul) nesta última década e principalmente após a crise financeira do capitalismo em 2008; a mobilização do Brasil no G-4, ao lado da Alemanha, Índia e Japão para reforma do Conselho de Segurança da ONU; a criação do Fórum de Diálogo Índia-Brasil-África do Sul (IBAS) em 2003; a criação da União das Nações Sul-americanas (Unasul) em 2008; a atuação do Brasil da Conferência sobre o Clima; a reforma no FMI com a ampliação da participação brasileira em 2010; o Brasil como sede da Copa do Mundo de 2014; o Rio de Janeiro como sede das Olimpíadas de 2016, além da criação de cinquenta novas embaixadas brasileira no exterior durante o governo Lula e na diversificação dos parceiros comerciais do Brasil (BARBOSA DA SILVA, 2011, p. 191).

\subsection{Prêmios Nobel de Literatura}

Quanto ao último critério observado, os prêmios Nobel de Literatura, podemos notar uma supremacia da língua inglesa, com 26 laureados, seguidos pela língua francesa e pela língua alemã, ambas com 13 ganhadores. O espanhol aparece na quarta posição com 11 laureados. Já o português divide com línguas de 
menor expressão, como o islandês e o provençal, a décima terceira posição, com apenas um ganhador: José Saramago.

\section{Quadro 4: Países Ganhadores do Prêmio Nobel de Literatura}

\begin{tabular}{|l|c|l|c|}
\hline $\begin{array}{l}\text { Língua dos } \\
\text { ganhadores }\end{array}$ & Prêmios & $\begin{array}{l}\text { Língua dos } \\
\text { ganhadores }\end{array}$ & Prêmios \\
\hline 1. Inglês & 26 & 13. Bengali & 1 \\
2. Francês & 13 & 13. Chinês & 1 \\
2. Alemão & 13 & 13. Tcheco & 1 \\
4. Espanhol & 11 & 13. Finlandês & 1 \\
5. Italiano & 6 & 13. Hebraico & 1 \\
5. Sueco & 7 & 13. Húngaro & 1 \\
7. Russo & 5 & 13. Islandês & 1 \\
8. Polonês & 4 & 13. Provençal & 1 \\
9. Norueguês & 3 & 13. Português & 1 \\
9. Dinamarquês & 3 & 13. Servo-croata & 1 \\
11. Grego & 2 & 13. Iídiche & 1 \\
11. Japonês & 2 & 13. Turco & 1 \\
13. Árabe & 1 & & \\
\hline
\end{tabular}

Fonte: Prêmio Nobel, $2011^{12}$.

Assim como alguns critérios acima, esse sofre influência da economia, mas também da ideologia da superioridade ocidental. Basta observar que as línguas no topo da lista são justamente aquelas mais valorizadas durante o século $X X$, principal período de entrega dos prêmios, como línguas de literatura e de "prestígio cultural" ou científico. Como se não bastasse, as línguas ocidentais representam países mais ricos, com maior poder editorial e com população mais alfabetizada, o que fomenta o consumo e a difusão de obras literárias. Cabe aqui perguntar que chances têm as línguas orientais, africanas, ameríndias, etc. de conquistar prêmios literários desse porte, se o mercado editorial é dominado pelas línguas europeias.

Após a apresentação desses dados, com diferentes critérios,

${ }^{12}$ Disponível em: $<$ http://nobelprize. org/nobel_prizes/literature/shortfacts.html> Acesso em: 08 ago. 2011. ${ }^{13}$ Calvet (2007), por exemplo, apresenta 37 dessas possibilidades. confirma-se que (1) diversas são as possibilidades de comparar duas ou mais línguas a fim de tentar demonstrar a importância de uma(s) sobre a(s) outra(s) ${ }^{13} \mathrm{e}(2)$ em muitos casos os dados não são precisos e as pesquisas não seguem metodologias com critérios explícitos. Por isso, há de se ter um olhar cuidadoso e crítico acerca de tais resultados, que não devem ser tomados como absolutos ou imparciais. 


\section{A CPLP e a lusofonia: o peso das variedades nacionais do português}

A polêmica da mensuração do peso das línguas não se restringe à competição entre as línguas supercentrais, mas estende-se às diferentes variedades nacionais de uma mesma língua. Devido a sua dimensão transcontinental e à heterogeneidade na constituição de diferentes identidades linguísticas nos países em que é falada, cada variedade nacional do português é única e apresenta características muito particulares.

A configuração do contato entre a língua da metrópole e as línguas autóctones das colônias - bem como as diferentes discursividades produzidas em torno delas - tornaram diferenciados os processos de colonização e descolonização em cada um dos países de língua oficial portuguesa. No caso dos Países Africanos de Língua Oficial Portuguesa (PALOP), a política assimiladora do regime colonial impôs medidas oficiais contra as línguas indígenas desde os primeiros anos de colonização. A violência simbólica da coibição e a falta de reconhecimento da alteridade pressupunha que os angolanos, moçambicanos e guineenses não tinham direito à língua ${ }^{14}$. Tratava-se de estados multiétnicos e multilíngues que o governo colonial pretendia unificar, pela força e pela coerção, em torno de uma única língua.

Portanto, a colonização linguística portuguesa na África gerou, de um lado, o encontro do português com outras línguas, e, de outro, um paulatino "desencontro" do português com ele mesmo; ou seja, "a partir dos novos sentidos construídos nas situações enunciativas oriundas dos contatos linguísticos é que surgirão uma língua e um sujeito nacionais" (MARIANI, 2004, p. 28). Isso significa, em última análise, que o português brasileiro, o português moçambicano, o português angolano, etc. são singularizados de acordo com as contingências históricas de cada colonização linguística e com as línguas de substrato e adstrato que lhes dão características de especificidade. A esse respeito, Perpétua Gonçalves declara, sobre a variedade do português de Moçambique:

O aspecto que mais sobressai na história da pesquisa sobre

14 ... enquanto no Brasil algumas línguas indígenas, como o Tupinambá, foram estudadas e gramaticalizadas pelos missionários jesuítas. Sobre as diferenças da colonização linguística portuguesa no Brasil e na Africa (Moçambique), conferir Mariani, 2011. as "variedades não nativas" (VNN) das línguas coloniais é que, durante muito tempo, estas constituíram uma espécie de parentes pobres da grande família das línguas naturais. [...] No que respeita ao contexto político-social, destaca-se o facto de, por emergirem em sociedades coloniais fortemente marcadas por preconceitos socioculturais e também raciais, as VNN terem sido vistas, durante muito tempo, como subproduto das línguas coloniais - os modelos "puros" e superiores criados pelos colonizadores - i.e., 
como línguas imperfeitas, geradas pelas populações colonizadas, que pareciam incapazes de aprender o padrão europeu na sua plenitude. (GONÇALVES, 2010, p. 13)

Essa situação não diz respeito apenas ao português, mas também às outras línguas coloniais, que são consideradas línguas pluricêntricas, termo primeiramente empregado por Kloss (1978, apud Clyne, 2004) para referir-se a línguas com diversos centros de interação, geograficamente contíguos ou não, cada qual estipulando uma variedade nacional com norma própria. Em geral, o status de diferentes variedades nacionais de uma língua pluricêntrica é assimétrico.

No caso da língua portuguesa, Portugal é a pátria-mãe desse idioma, enquanto que o Brasil tem um território e uma população muito maiores e, atualmente, maior poder econômico. Essas características podem levar a uma relação simétrica das variedades nacionais do português brasileiro e do português europeu em termos de status, apesar de suas diferenças. Não obstante, tal simetria não se aplica a países como Angola, Moçambique, Guiné-Bissau, Cabo Verde e Timor-Leste, nos quais o processo de colonização envolveu a imposição violenta da língua europeia. Em tais lugares, permanece ainda nos dias de hoje um imaginário de deficiência e subserviência produzido no período colonial. Os efeitos de controle, exclusão e violência simbólica a que foram submetidos os povos africanos deixaram consequências que se vêem ainda hoje no período pós-colonial, herdeiro da ideia de que as línguas não européias são dificultosas, defeituosas, sem racionalidade (MARIANI, 2004, 2005 e 2011).

Em relação a isso, as variedades nacionais que têm mais visibilidade e representatividade - como o português europeu e o brasileiro - apresentam características como a noção de que elas é que são o standard, enquanto as outras são não-standard, exóticas ou arcaicas; além disso, sustenta-se a crença de que têm normas mais rígidas, maior uniformidade na escrita, melhores recursos para exportar sua variedade em programas de ensino de língua, bem como para publicar gramáticas, dicionários e livros didáticos (CLYNE, 2004).

Analisando mais detalhadamente os dados estatísticos sobre

15 Esse número total de falantes da língua portuguesa leva em consideração além da população dos países lusófonos, os imigrantes lusófonos fora dos países de língua portuguesa e os estrangeiros que falam português como língua estrangeira (LE). a língua portuguesa na atualidade, notamos a concentração de falantes em um único país. Os brasileiros falantes de língua portuguesa como materna respondem por $82,4 \%$ de todos os falantes de português no mundo todo (LEWIS, 2009; BANCO MUNDIAL, $2009)^{15}$. O gráfico 2 foi desenhado a partir de estimativas populacionais de falantes de português tanto como LM quanto L2 nos países lusófonos e no exterior. 
Gráfico 2: Distribuição dos falantes de português entre países lusófonos e língua materna/segunda língua

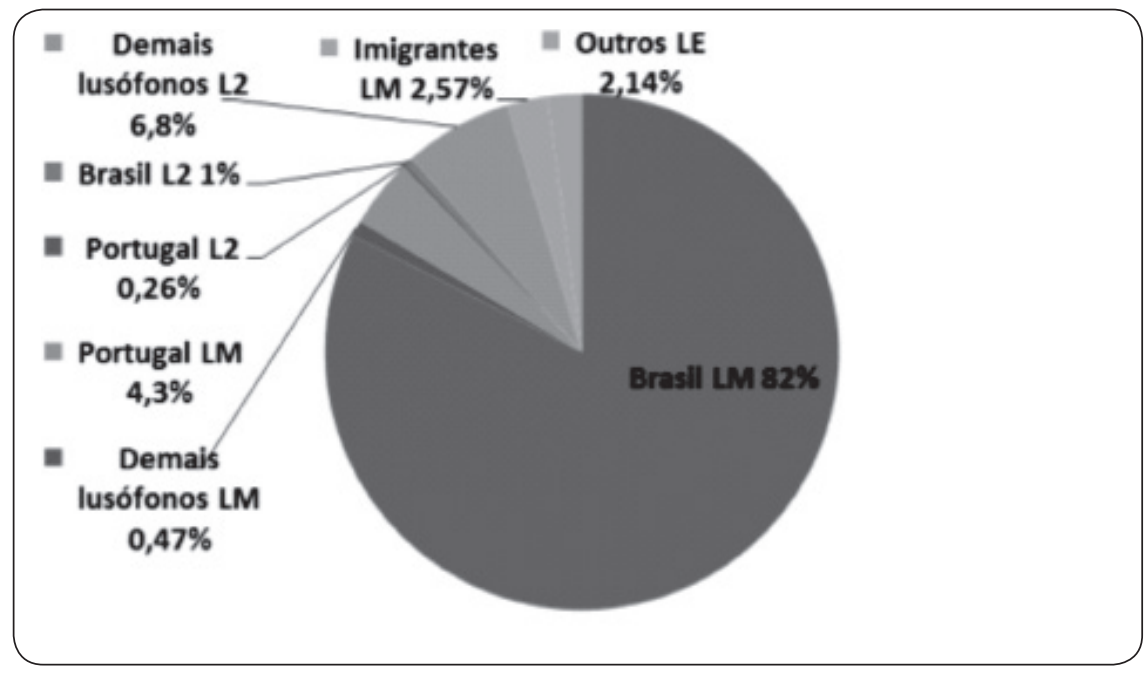

Fonte: Barbosa da Silva, 2011, com base nos dados do IBGE, The New Times Almanac, LEWIS. Ethnologue, 2009 e institutos estatísticos de países de língua oficial portuguesa.

Como se vê no gráfico, somando os falantes de português como língua materna (LM) e segunda língua (L2) de cada país, o Brasil responde por $83,4 \%$ dos falantes no mundo, enquanto Portugal apenas 4,5\%. Percebe-se também neste gráfico que a quantidade de falantes de português nos Países Africanos de Língua Oficial Portuguesa e no Timor ainda é pequena, pois apesar de responderem por $18 \%$ da população da CPLP, eles contribuem com apenas 7,3\% dos falantes de português em todo o mundo, levando em consideração o somatório dos falantes, nesses países, de português como LM e L2 (LEWIS, 2009). Isso significa que a maioria da população nos países africanos de língua portuguesa e no Timor-Leste não fala português.

Não obstante, em todas as diferenças socioeconômicas e culturais entre os países de língua oficial portuguesa existem um interesse e um investimento por parte dos Estados em promover a valorização e a inserção da língua portuguesa no cenário internacional, em alianças diplomáticas estratégicas para uma cooperação com base na língua comum. Em 1989, por exemplo, ocorreu a primeira reunião desses países, com a consequente criação em 1996 da Comunidade dos Países de Língua Portuguesa (CPLP), órgão que "se assume como um novo projeto político, cujo fundamento é a língua portuguesa"16. Com a CPLP, é criado também o Instituto Internacional da Língua Portuguesa - ideia lançada pelo então presidente brasileiro José Sarney -, cuja sede situa-se na capital de Cabo Verde, a cidade de Praia. Segundo Faraco (2009), “apesar

${ }^{16}$ Conferir o site: www. cplp.org dos esforços dos seus dirigentes, (o instituto) estava já em 2004 em estado de falência técnica. Mesmo equilibradas suas finanças, sua 
ação tem sido pífia". Durante os anos do governo Lula (2003-2010), as relações Sul-Sul - entre Brasil, os PALOP e o Timor-Leste - foram uma preocupação constante da agenda da política externa brasileira (ZOPPI-FONTANA, 2009, p. 14; FARACO, 2009; AYLLÓN e LEITE, 2010; BARBOSA DA SILVA, 2012).

No entanto, se por um lado os discursos defendem a unidade política, por outro lado revelam o desnível entre a força política dos membros da CPLP, como percebemos na declaração do diplomata Leonardo Lott (2009), chefe da Divisão de Promoção da Língua Portuguesa do Departamento Cultural do MRE: "Brasil e Portugal devem harmonizar seus interesses, pois os demais países lusófonos irão atrás" e Portugal já percebeu que "se o Brasil garantir uma vaga permanente no Conselho de Segurança da ONU, é o português brasileiro que estará lá".

Nota-se, nesses discursos oficiais, nas entrelinhas de uma pretensão de simetrização entre os países da CPLP, um tom de superioridade por parte de Brasil e Portugal, e também certa competição entre as variedades nacionais dos dois países. Fiorin, sobre tal questão, defende

Para que a lusofonia seja um espaço simbólico significativo para seus habitantes, é preciso que seja um espaço em que todas as variantes linguísticas sejam, respeitosamente, tratadas em pé de igualdade. É necessário que não haja autoridade paterna dos padrões lusitanos. (...) A lusofonia não será pátria, porque não será um espaço de poder ou de autoridade. Será mátria e será frátria, porque deve ser o espaço dos iguais, dos que têm a mesma origem. Se assim não for, ela não terá nenhum significado simbólico real, será um espaço do discurso vazio de um jargão político sem sentido (FIORIN, 2006,p. 46).

Ora, o âmbito do que hoje se chama lusofonia comporta tanto países em que o português é adotado com língua materna da esmagadora maioria da população, como Brasil e Portugal, quanto países que têm o português como língua oficial, porém não majoritária, como os PALOP e Timor-Leste, e ainda aquelas comunidades em que o português é a língua de uso e comunicação para apenas uma pequena parte da população, como Goa, na Índia, e Macau, na China (BRITO, 2003; PONSO, 2011b).

Tal desigualdade é percebida de maneiras diferentes por linguistas portugueses, brasileiros e africanos, que encaram a lusofonia desde pontos de vista nem sempre concordantes; enquanto aqueles parecem buscar uma certa redenção ou reparação da época colonial e imperialista e "a continuidade da dominação com outra roupagem" (FARACO, 2009, p.11), esses apoiam-se no discurso da lusofonia "como parte de uma estratégia de projeção geopolítica do país" (ibid. 10), e estes últimos - na maior parte das vezes - não se sentem representados pela "fonia lusa".

O sonho lusófono dos portugueses, anunciado por Eduardo Lourenço "como um espaço de refúgio imaginário, o espaço de 
17 Sobre essa questão da heterogeneidade, diz Mia Couto (no evento mencionado na nota 2): “Os lusófonos são pensados e falados do seguinte modo: Portugal, Brasil e os PALOP [Países Africanos de Língua Oficial Portuguesa]. Surgimos como um triângulo com vértices um no Brasil, um em Portugal e um terceiro em África. Ora, os países africanos não são um bloco homogéneo que se possa tratar de modo tão redutor e simplificado. Não se pode conceber como uma única entidade os 5 países africanos que mantêm, entre si, diferenças culturais sensíveis. As nações lusófonas não são um triângulo, mas uma constelação em que cada um tem a sua própria individualidade". uma nostalgia imperial, que os ajude hoje a sentirem-se menos sós e mais visíveis nas sete partidas do mundo" (LOURENÇO, apud MARTINS, 2006) está impregnado de uma idealização romântica, de uma monumentalização da língua (ZOPPI-FONTANA, 2009), que prega a irmandade, a solidariedade, a cooperação, a tolerância:

Como espaço de cultura, a lusofonia não pode deixar de nos remeter para aquilo que podemos chamar o indicador fundamental da realidade antropológica, ou seja, para o indicador de humanização, que é o território imaginário de arquétipos culturais, um inconsciente coletivo lusófono, um fundo mítico de que se alimentam sonhos. (MARTINS, 2006, p. 30)

Tal discurso apaga, ou no mínimo abranda em muito, os conflitos e ressentimentos resultantes da violenta colonização portuguesa na África:

Nesse discurso de exaltação e celebração, não há, evidentemente, espaço para uma leitura crítica da exploração colonial. Ou do papel central que os luso-brasileiros exerceram no tráfico internacional de escravos africanos durante 300 anos; não há espaço para discutir o estado de imensa miséria social, econômica e cultural em que foram deixados, no momento da independência, os territórios africanos e asiáticos que estiveram sob o domínio português; não há espaço para deixar visíveis a ideologia e as práticas racistas do colonialismo português na África; não há também espaço para compreender a heterogeneidade dos diferentes países, salvo se ela puder ser reduzida ao exótico e devidamente folclorizada (a culinária, por exemplo $)^{17} \mathrm{e}$, mais ainda, não há espaço para se reconhecer e discutir o fato de que a língua portuguesa funciona socialmente também como forte fator de discriminação e exclusão nas sociedades em que é falada (FARACO, 2009).

Segundo Eduardo Namburete (2006, p. 63), professor do curso de Comunicação Social da Universidade Eduardo Mondlane de Moçambique, o termo lusofonia "ainda constitui um pólo de divergência, pois o seu entendimento ainda não é compartilhado por todos aqueles que deveriam nela se sentir representados". O autor questiona a identidade linguística de tantos falantes que vivem em países ditos lusófonos, mas que "não falam, não leem e muito menos escrevem na língua de Camões" e afirma que tal tema é inevitavelmente enfrentado do lado africano com ceticismo e nem sempre de forma pacífica.

Pretendemos ainda consubstanciar a nossa recusa à congregação dos países africanos de expressão oficial portuguesa sob o manto da lusofonia usando para tal o argumento de que em português todos nós nos entendemos. Recusamo-nos a perpetuar a falsa verdade de que os países africanos colonizados por Portugal se comunicam usando os fones lusos. Moçambique estaria mais bem categorizado no grupo dos países bantúfonos (op. cit. p. 70). 
Essa asserção é confirmada em recente artigo de Nataniel Ngomane, professor da mesma Universidade:

Não sou, necessariamente, um indivíduo de expressão portuguesa. Não sou lusófono, mesmo porque minha matriz fundamental é bantu. E não nasci apenas eu: mas irmão. "Expressão" refere-se ao ato de exprimir. Representação escrita, palavra, frase, não se restringindo, como pode parecer - à fala (ou à escrita), à expressão verbal. [...] Esses aspectos têm mais a ver com questões socioculturais, cuja amplitude ultrapassa confinamentos linguísticos. [...] Aplicar essa expressão (lusófono, lusofonia) a indivíduos, povos, países e outras entidades não-portuguesas, equivale a atribuir - e de forma matreira! - qualidades ou características portuguesas a entidades que, não sendo portuguesas, acabam por ter-e-ver apagadas e esvaziadas suas próprias características. (NGOMANE, 2012)

Percebe-se, nas citações acima, a diferença de sentidos que o termo lusofonia assume quando é visto do ponto de vista de linguistas portugueses, brasileiros ou africanos e também o diferente estatuto de que goza a língua portuguesa no contexto social de cada país onde é falada. Para Nascimento (2010, p. 6), a CPLP ancora-se na língua, que ilusoriamente pode representar um espaço de continuidade, suprindo as descontinuidades geográficas, sócio-históricas e culturais dos seus países membros. $\mathrm{Na}$ verdade, nada mais heterogêneo do que as formas de expressão - verbais e não verbais - de angolanos, brasileiros, goenses, timorenses, moçambicanos.

Portanto, se no futuro a lusofonia se pretende um espaço de intersecções e imbricações culturais, deve desde já questionar o estatuto de universalidade e de hegemonia do português e contemplar as línguas que coabitam esse espaço com ele. A CPLP, embora tenha traços de uma herança linguística cultural comum, tem uma conformação plural e diversa, que deve ser reconhecida e compartilhada pelos seus membros a fim de que a cooperação para o fortalecimento do idioma seja mais efetiva do que retórica.

\section{Conclusão}

A sociometria das línguas, como demonstramos na primeira parte deste trabalho, apresenta grande divergência tanto quanto aos critérios de medição do peso relativo das línguas, como quanto às intenções que motivam e direcionam as pesquisas, o que exige um olhar sempre crítico sobre os seus resultados. Ao mesmo tempo em que a demografia linguística pode comprometer-se com demandas políticas, ideológicas, sociais, econômicas relacionadas à defesa dos Estados-nação, paralelamente também pode erigir e manter um estatuto para as línguas.

No que se refere à lusofonia, que abordamos na segunda parte, uma relação assimétrica entre o estatuto das diferentes variedades nacionais da língua portuguesa pode comprometer o seu estatuto como idioma transnacional. De fato, o surgimento 
de um mercado linguístico global e o processo de capitalização linguística, impulsionados pelo crescimento econômico acelerado do Brasil nos últimos anos, produzem uma expansão cada vez maior do idioma. Todavia, órgãos como a CPLP produzem um discurso de unidade que, apesar de afirmar ter como "fundamento a língua", fundamentam-se em relações de supremacia político-econômica, que por vezes revelam uma competição entre as variedades nacionais do português, especialmente o europeu e o brasileiro.

Independentemente de sua relação ou não com a colonização linguística ou com a hiperidentidade portuguesa, os discursos em torno da lusofonia apostam na unidade em torno da língua. Tal tentativa tem como consequências a desvalorização das variedades não nativas do português, a assimetria dos estatutos dessas variedades nacionais, o desconhecimento dos ambientes multilíngues de muitos dos Estados que a compõem, e, sobretudo, da heterogênea realidade linguística desses países.

O efeito de negar as assimetrias dos estatutos das variedades nacionais para forjar uma unidade linguística, bem como o processo de capitalização linguística tão útil para os governos, mostram quão frágil pode ser essa lusofonia se não for respaldada por políticas culturais transnacionais baseadas na diversidade. Todo esse panorama envolve consequências tanto para as políticas de expansão e inserção do português no espaço político internacional, quanto para as análises sociométricas do estatuto do idioma.

\begin{abstract}
Sociometry, the study of rankings and hierarchies between languages, is discussed critically in this paper from two problems involving the Portuguese language. The first refers to the defense of lusophony in face of other languages, in an attempt to maintain a linguistic unity among Portuguese-speaking countries. The second refers to the existing asymmetry of the the Portuguese language variations, which are sometimes intentionally ignored. Since it is a polemic issue, the sociometric surveys show wide divergence as well as criteria for measuring how much the authors' intentions that motivate and direct these studies. Thus, they feed a competition that has no linguistic basis; however, it suits the political, social, ideological and economic States - while erasing the affirmation of diversity and heterogeneity. The fragile idea of lusophony appears in this troubled context.
\end{abstract}

Keywords: Portuguese language; variety of language; lusophony; sociometry. 


\section{REFERÊNCIAS}

ÁFRICA 21. Zâmbia introduz língua portuguesa no currículo escolar, 17 abr. 2009. Disponível em:

$<$ http://www.africa21digital.com/noticia.kmf?cod=8349505\&canal=403> Acesso: 19 jun. 2010.

ANDERSON, Benedict. Comunidades Imaginadas. São Paulo: Companhia das Letras, 2008.

AYLLÓN, Bruno \& LEITE, Iara. La cooperación Sur-Sur de Brasil: Proyección solidaria y política exterior. In: AYLLÓN, Bruno \& SURASKY, Javier (coords.). La cooperación Sur-Sur em Latinoamérica. Madrid: UCM, 2010.

BANCO MUNDIAL. Indicadores. Disponível em: <http://data.worldbank.org/indicator> Acesso em: 10 abr. 2010. BARBOSA DA SILVA, Diego. De Flor do Lácio à língua global: uma análise discursiva das relações de poder nas políticas linguísticas para a promoção, a difusão e a projeção do português da Comunidade dos Países de Língua Portuguesa (CPLP). Dissertação (Mestrado em Letras) - Instituto de Letras, Universidade do Estado do Rio de Janeiro, Rio de Janeiro, 2011.

- O Brasil na CPLP: A cooperação técnica horizontal para (além d)o desenvolvimento. Monografia (Especialização em Relações Internacionais Contemporâneas) - Instituto de Relações Internacionais, Pontifícia Universidade Católica do Rio de Janeiro, 2012.

BBC BRASIL. Uruguai ensinará português em escolas públicas a partir de 2010, 22 abr. 2009. Disponível em:

$<$ http://www.estadao.com.br/noticias/geral,uruguai-ensinara-portugues-nas-escolas-publicas-a-partir-de-2010,358706,0. htm> Acesso em: 17 ago. 2010.

BRITO, Regina Helena Pires de. Quatro contextos, uma língua: reflexões em torno da lusofonia. In: $1^{\circ}$ Colóquio Anual da Lusofonia da SLP, 2002. Actas. Porto: Sociedade de Língua Portuguesa, v. 1, p. 1-17, 2002.

CALVET, Louis-Jean. Globalización, lenguas y políticas lingüísticas. In: Synergie. Santiago, 2005. Disponível em: http://perso. wanadoo.fr/Louis-Jean.Calvet/ Acesso em: 06 janeiro de 2008.

Press, 2006.

Towards an Ecology of World Languages. Cambridge: Polity

O Peso das Línguas. In: I Encontro Internacional do GT de Sociolinguística da ANPOLL, ocorrido na PUC-Rio entre 31 de julho a 3 de agosto de 2007. Tradução de Telma Pereira, 2007.

CIA. Central Intelligence Agency of the United States. Disponível: <https://www.cia.gov/> Acesso em: 28 jul. 2011. 
CLYNE, Michael. “Pluricentric Languages”In AMMON, H. V. U.; DITTMAR, N. \& MATTHEIR, K. J. Sociolinguistics: An International Handbook of the Science of Language and Society, Vol. 1. Berlin/ New York: Walter de Gruyter, 2004.

CRYSTAL, David. English as global language. Cambridge: Cambridge University Press, 1997.

DEUTSCHLAND. Revista Deutschland. Lingua das ideias: qual o papel do alemão no mundo?, 17 mai. 2010. Disponível em:

$<$ http://www.alemanja.org/alemanha-lingua/1828-lingua-dasideias-qual-o-papel-do-alemao-no-mundo> Acesso em: 15 ago. 2010.

DINIZ, Leandro Rodrigues Alves. Mercado de Linguas: a instrumentalização brasileira do português como língua estrangeira. Campinas; RG, 2010.

ESPERANÇA, José Paulo; ISCTE, Instituto Superior de Ciências do Trabalho e da Empresa. Uma abordagem eclética do valor da língua: a influência global do português. Lisboa: ISCTE, 2008. Disponível em: <http://www.instituto-camoes.pt/noticias-ic-portugal/ lingua-representa-17-do-pib-em-portugal.html> Acesso em: 14 jan. 2010.

ETHNOLOGUE. Disponível em: <http://www.ethnologue.com/> Acesso em: 25 jul. 2011.

EXTRA, Guus; YAĞMUR, Kutlay. Urban Multilingualism in Europe: Immigrant Minority Languages at Home and School. Clevedon: Multilingual Matters, 2004.

FARACO, C. A. Lusofonia: utopia ou quimera? Língua, história e política. In: Conferência de encerramento do ROSAE - I Congresso Internacional de Linguística Histórica. Salvador, Bahia, 2009.

FIORIN, José Luiz. A lusofonia como espaço linguístico. In: BASTOS, Neusa Barbosa. Lingua Portuguesa: reflexões lusófonas. São Paulo: EDUC, p. 25-48, 2006.

FIRMINO, Gregório. A questão linguística na África pós-colonial: o caso do português e das linguas autóctones em Moçambique. Maputo: Promedia, 2002.

FMI. Fundo Monetário Internacional. Disponível em: <http://www.imf.org/external/index.htm>. Acesso em: 28 jul. 2011.

GONÇALVES, Perpétua. A Génese do Português de Moçambique. Maputo: Impensa Nacional-Casa da Moeda, 2010.

GUIMARÃES, Eduardo. Política de línguas na linguística brasileira. In: ORLANDI, Eni (org). Política linguística no Brasil. Campinas: Pontes, 2007.

HAMEL, Rainer Enrique. La globalización de las lenguas en el siglo XXI entre la hegemonia del Inglés y la diversidad lingüís- 
tica. In: DA HORA, Demerval; LUCENA, Rubens Marques (orgs.). Política Linguística na América Latina. João Pessoa: Ideia, 2008a.

. Les langues de la science: (A) Vers un modèle de diglossie gérable. In: MAURAIS, J; DUMONT, P et al. L'avenir du français. Paris: Éditions des archives contemporaines et em partenariat; l'Agence universitaire de la Francophonie (AUF), $2008 \mathrm{~b}$.

HISTÓRIA SIGLO 20. Disponível em:

$<$ http://www.historiasiglo20.org/HE/6c.htm> Acesso em: 10 nov. 2010.

HOBSBAWM, Eric. Nações e nacionalismo desde 1780. Rio de Janeiro: Paz e Terra, 1990.

KACHRU, Braj B. The alchemy of English: The spread, functions, and models of non-native Englishes. Oxford: Pergamon Institute of English, 1986.

LEWIS, M. Paul (edit.). Ethnologue, Languages of the World. Dallas: Sil International, $16^{\mathrm{a}}$ edição, 2009.

LOTT, Leonardo, A política de promoção da língua portuguesa implementada pelo Departamento Cultural do Itamaraty: realidade e desafios. In: III Encontro Nacional sobre Politicas de Lingua(s) e Ensino. Brasília: ALAB, 2009.

MARGARIDO, Alfredo. A Lusofonia e os Lusófonos: Novos Mitos Portugueses. Editoras Universitárias Lusófonas: Lisboa, 2000.

MARIANI, Bethania. Colonização Linguística. Campinas: Pontes, 2004.

. Da colonização linguística portuguesa à economia neoliberal: nações plurilíngues. In Gragoatá, número 24, 2005.

Língua portuguesa, políticas de línguas e formação de Estados nacionais: notas sobre lusofonia. In: PONTES, Geraldo; ALMEIDA, Claudia (coords.). Relações literárias internacionais: Rio de Janeiro: Eduff; de letras, p. 234-253, 2007.

. Língua, colonização e revolução: discurso político sobre as línguas em Moçambique. In: Abril, vol. 4, n 7, nov. 2011.

MARTINS, Moisés de Lemos. "Lusofonia e luso-tropicalismo. Equívocos e possibilidades de dois conceitos hiper-identitários" In: BASTOS, Neusa Barbosa. Lingua Portuguesa: reflexões lusófonas. São Paulo: EDUC, p. 49-62, 2006.

MUNDO PORTUGUÊS. Venezuela: Português deverá ser língua de opção no ensino oficial, 25 mai. 2009. Disponível em:

<http://www.mundoportugues.org/content/1/4769/venezuela-portugues-devera-ser-lingua-opcao-ensino-oficial/> Acesso em: 15 ago. 2010.

NAMBURETE, Eduardo. Língua e lusofonia: a identidade dos que não falam português In: BASTOS, Neusa Barbosa. Lingua Portuguesa: reflexões lusófonas. São Paulo: EDUC, p. 63-74, 2006. 
NASCIMENTO, Augusto - Lusofonia, que perspectivas culturais?. In: Ciclo de conferências Encontros com a História. Maputo, 2009. Disponível em: <http://cvc.instituto-camoes.pt/index.php?option $=$ com_docman\&task $=$ cat_view\&gid $=934 \& I t e m i d=69>$ Acesso em: 19 set. 2011.

NATALI, Adriana; PINHO, Lílian. O Brasil flerta com a vizinhança. Revista Lingua Portuguesa. Disponível em:

$<$ http://revistalingua.uol.com.br/textos.asp?codigo=11539> Acesso em: 20 set. 2009.

NGOMANE, Nataniel. Lusofonia: quem quer ser apagado? Disponível em: < http://ma-schamba.com/ficheiros/Ngomane1.jpg> Acesso em: 26 abr. 2011.

OBSERVATÓRIO DA LÍNGUA PORTUGUESA. Disponível em: <http://observatorio-lp.sapo.pt/pt> Acesso em: 27 jul. 2011.

ORLANDI, Eni. Lingua e conhecimento linguístico: para uma história das ideias no Brasil. São Paulo: Cortez Editora, 2002.

. Lingua Brasileira e Outras Histórias: Discurso sobre a lingua e ensino no Brasil. Campinas: RG editores, 2009.

OUANE, Adama (org). Towards a multilingual culture of education. Hamburgo: Unesco Institute for Education, 2003.

PONSO, Letícia Cao. O português no contexto multilíngue de Angola. In: Confluência - Revista do Instituto de Língua Portuguesa, Rio de Janeiro, n. 35/36, p. 147-162, 2009.

. Políticas linguísticas atuais em Angola e Moçambique: o modelo monolinguista do Estado nacional europeu X o modelo plurilíngue das nações africanas. In: XI Congresso Luso-afro-brasileiro de Ciencias Sociais. Anais. Salvador, 2011a.

. Um foco sobre a situação sociolinguística dos Países Africanos de Língua Oficial Portuguesa. In: Revista Icarahy, formato eletrônico,no 5, 2011b. Disponível em:

$<$ http://www.revistaicarahy.uff.br/revista/html/numeros/5/ dlingua/LETICIA.pdf>

PRÊMIO NOBEL. Disponível em:

<http://nobelprize.org/nobel_prizes/literature/shortfacts.html> Acesso em: 08 ago. 2011.

RATTNER, Jair. Congo passaráa ensinar português nas escolas, 04 jun. 2010. Disponível em:

$<$ http://www.estadao.com.br/noticias/arteelazer,congo-passara-a-ensinar-portugues-nas-escolas,561666,0.htm> Acesso em: 16 jun. 2010.

RONCARATI, Cláudia (org.). Difusão da língua portuguesa. Cadernos de Letras da UFF, no 39, 2009. 
Sociometria dos estatutos da expansão transnacional da língua portuguesa. Projeto de Bolsa de Produtividade em Pesquisa submetido ao CNPq, 2011.

SARAIVA, José Flávio Sombra. Política exterior do Governo Lula: o desafio africano. Revista Brasileira de Política Internacional, Brasília 45 (2), p. 5-25, 2002. Disponível em:

<http://www.scielo.br/scielo.php?pid=S0034-7329200200 0200001\&script=sci_abstract> Acesso em: 15 dez. 2010.

WIKIPEDIA (em português). Disponível em:

$<$ http://pt.wikipedia.org/wiki/Anexo:Lista_de_1\%C3\%ADnguas_por_total_de_falantes> Acesso em: 30 jul. 2011.

WORLD'S OBSERVATORY. Disponível em:

$<$ http://frankherles.wordpress.com/2008/10/29/os-100-idiomasmais-falados-do-mundo/>. Acessos entre 25 e 30 jul. 2011.

WRIGHT, John W. (edit.). The New York Times Almanac 2009. New York: Penguin Reference, 2008.

UNESCO. Disponível em: <http://www.abec.ch/Portugues/ subsidios-educadores/artigos/categorias/artigos-familia/Portugues_e_a_sexta_lingua_materna_mais_falada_no_mundo.pdf $>$ Acesso em: 30 jul. 2011.

ZOPPI-FONTANA, Mónica (org.). O português do Brasil como língua transnacional. Campinas: Editora RG, 2009. 